\title{
SUSTAINABLE SPATIAL DEVELOPMENT AND CHANGE IN PLANNING
}

\author{
Kauko Tom \\ Independent scholar (HUNGARY) \\ Tomjkauko[at]gmail.com
}

\begin{abstract}
Urban planning is facing conceptual challenges caused by increased uncertainty, diversity and incommensurability of goals. Therefore, an approach based on seemingly rational linear models of delivery is long overdue. This article first examines the sustainability agenda to the extent it can serve as an overall framework for different approaches to spatial development and planning. After that, the concepts diversity, polycentricity and resilience are examined with similar aim. The reviewed interdisciplinary literature suggests that sustainability is a concept that works at a general level, but the three other concepts require considerable detail. Thus, when focusing on these concepts, a bottom-up approach is preferred to a top-down one. Here it can be noted that the most detailed issues can only be reached when they result from private investment activity aimed at incremental improvement and conversion at site-level. If this is not a feasible, an alternative route to successful planning practice would be to direct attention to more pressing current urban social problems.
\end{abstract}

\section{Keywords: Diversity, Planning, Polycentricity, Resilience, Sustainability}

\section{INTRODUCTION}

Urban planning systems have undergone fundamental changes throughout the last century or so. Dominant ideals have shifted from 'city beautiful', to social and health issues, and from modernism to postmodernism, to name but a few. While defining planning in general terms as resource allocation, in the current age of short-term gratification, the tendency is to sell what resonates with the masses - rather than to sell the scientific rationale and evidence per se. In other words, what seems to matter most is of a socio-cultural (and often popular) kind: to create an opportunity to inform the decision-making communities related to the urban environment, before actually improving the quality of the urban environment. 
Planning is of course still not a monolithic concept. We can for instance distinguish between strategic and operational planning: the former is about coordinating activities of various parties; the latter is about how specific plots of land are to be used [1]. At any rate, the consensus is that traditional planning is seen as being in crisis. When deliberating any remedies for this, the approaches vary to the extent the system of values changes [2]. To some extent, the variation is also depending on if the basis is supposedly scientific or not. ${ }^{1}$ Usually planning is understood as a set of rules and regulations that today also involve negotiations and bargaining [4]. One should furthermore realise that any institutional circumstances are likely to change through time, for example, the regulations regarding the amount of public space become stricter, or the market for the end product collapses [5-6].

The aim of this contribution is to examine multiple definitions of debated planning and development concepts in an urban setting. The focus is on the theoretical background of urban development and, in particular, the validity of selected popular late-modern spatial development concepts therein. The assumption here is that it is important that we define concepts clearly, especially, concerning the need for urban planning to change with times. Here interdisciplinary perspectives are put together.

The paper is organised as follows. After this introduction, section 2 examines the sustainability agenda to the extent it can serve as a common denominator for a number of current approaches to planning. In section 3 the concepts resilience, polycentricity and diversity are examined in this vein. Conclusions are drawn in section 4.

\section{SUSTAINABLE PLANNING; PLANNING SUSTAINABILITY}

Sustainable planning could, in principle, imply guaranteeing a sustainable development and management of the built environment. For example, a sustainable plan-making approach based on steps of planning, action and implementation has been suggested [7]. Here are, however, two problems or dilemmas. Firstly, planners and the planning regulations do not have the power over how sustainable the built environment will become - they can only try to moderate, facilitate and direct mostly private investments which, in any case, requires gaining the trust of actors such as pension funds, banks, or insurance companies. Especially clear this is in a context where funds are limited such as in post-socialist circumstances. Secondly, even if planners had such power, the sustainability would not be absolute, but about a trade-off between various levels of sustainable development in different dimensions (i.e. environmental, ecologic, social, cultural and economic). For example, building ecological sites surrounded by green areas might be inaccessible by public transport or bicycling.

\footnotetext{
${ }^{1}$ The debate concerns the justifications of any given approach. For example, the implementation of school improvement strategies in developing countries can be considered an ungrateful planning exercise, insofar as it tends to be decided based on political rather than scientific rationale: leaders want to pick a strategy that pleases the electorate, rather than mitigate a problem in earnest [3]. In this case, Mircea Enache writes about a Minister of Education who had commissioned collection of some 14,000 data items, including the number of ping pong tables, balls and nets in each school. This despite the fact that such indicators have never shown to affect school performance - the only significant explanations in this context being about the education level of parents and teachers, which Enache points out.
} 
Thus, external constraints matter for how sustainability goals are set. Timothy Chapin notes that in the emerging Era of Sustainable Growth, growth is still seen as inevitable and essential, but is now being balanced against the long-term goal of sustainability [8]. In this context Smart Growth is considered the essential tool, as its approach is to improve communities rather than seeing them as problems that require government control. Chapin concludes that the private sector has been active in such evolving planning initiatives. However, others argue that Smart Growth unfortunately (for the overall goal of sustainable growth) ignores industrial land, and that this is foolish from an economic development point of view [9].

Energy issues are often seen as being at the core of the specifically 'green' sustainability agendas. Even if these issues have been recognised broadly since 1990 s, here is still work to be done. While energy aspects are addressed at the level of building, they are still missing at the levels of housing or business park developments, quarters and districts [10]. In this way we move towards a whole city perspective of energy efficiency.

The sustainable city also relates to other similar new concepts such as smart city, eco city, green city or low-carbon city $[11] .^{2}$ Freiburg (Germany) is often considered one of the most sustainable cities in the world. This city's key to success is developing their 'smart city vision' as part of a broader 'Green City' concept with ambitious energy goals. The global network Local Governments for Sustainability (ICLEI) also promote a view where citizens are seen as being 'at the heart of the smart city thinking'. This development is enabled by new technologies with 'possibilities for involving people in every step of the decision-making process' [13]. ICLEI furthermore states that this 'is an opportunity for people to re-appropriate the environment in which they live and develop a new sense of community'. This smart city approach is based on innovative, inclusive solutions to improve life for all citizens [13].

Within this paradigm social and economic sustainability measures are particularly difficult to sort out [14]. Social sustainability has been approached comprehensively by Tony Manzi and colleagues [15-16], whose starting point is to define sustainability in terms of social equity, access to resources, participation, social capital, human rights and exclusion. While precise causal relationships are uncertain, policies to ameliorate the negative environmental and socio-economic externalities are necessary to ensure sustainable communities, these authors argue. Manzi and colleagues also raise concerns about the competence of governments to steer partnerships and networks in order to achieve social sustainability; more specifically, by incorporating a wider range of stakeholders in the delivery of urban processes embracing inclusion, care and governance [16].

Manzi and colleagues define sustainable communities by the Egan Whee/ model of eight sectors [16]: governance, transport and connectivity, services, environment, equity, economy, housing and the built environment, and social and cultural factors. However, this agenda [sic] neglects the political dimensions. These authors assert that, despite conceptual flaws and practical difficulties, social sustainability is important guiding principle for direction of policies and environment; furthermore, it is inseparable in relation to environmental and economic dimensions [16]. The

\footnotetext{
${ }^{2}$ In similar vein, Daniela Antonescu lists the following concepts related to liveability analysis: sustainable-city, smart-city, global-city, perfect-city and fastest-city [12].
} 
overall conclusion of Manzi and colleagues is that social sustainability requires investment and not only plans [15].

In the urban context social sustainability has been approached in many different ways. In England some experts champion the case of Community Land Trusts, because of their creativity demonstrated in relation to financial viability models of sustainable housing provision [17]. This is also an argument for a more anthropocentric model, rather than the eco-centric model that still today dominates the sustainability agenda. Another view defines sustainable communities as places where people want to live and work now and in the future [18]. However, according to others, sustainable community and social equity concepts are not established at a spatial scale that would be agreed upon. In conclusion, the problem here [sic] is agency at the neighbourhood level and undermining of community infrastructure [19].

According to Emily Talen, the challenge for planners is to differentiate the evaluation criteria for sustainable urban form in relation to what the total best for a given place is, and in general, to take the existing constraints into consideration [20]. She suggests that planners ought "to evaluate the potential of some places to be catalysts for an improved - more sustainable - urban form" using a method based on the potential for retrofit [7, 21-23]

On the other hand, Andrea Colantonio and Tim Dixon consider social capital a contested concept, but at the same time a component of social sustainability, as it is argued that strong communities need social capital and good governance [24]. Furthermore, urban sustainability is central in two discourses: one, how cities impact sustainable development; and two, what the components of urban sustainability are (e.g. density increase either improves or reduces the urban sustainability evaluation; or a compact infrastructure facilitates social interactions or not). Such issues are recently incorporated into planning and urban regeneration agendas. The difficulty, alas, is "the speculative nature of social sciences", and to develop a metrics and tools for social sustainability [24].

All these disparate and emerging issues indicate an apparent need for more precise conceptualisation of sustainable development. Some solutions require top-down actions, whereas others require more of a bottom-up approach. It is furthermore important to admit that despite planning for change, not all changes can be foreseen [25]. In this vein, Ramin Keivani notes that the two-way interaction between environmental concerns and social and economic domains is mediated through physical space and built form, and that in principle, these interactions can be moved to either a virtuous circle of development or to the reverse outcome [26]. However, here any critique ought to be founded in realities, and informed by already existing best practices [27].

Trade-offs and overlaps between sustainability dimensions notwithstanding, evidently, sustainability means different things at different levels of conceptualising. It is therefore only at relatively general level that we can find common ground in order to build further theoretical and methodological points based on the vision of sustainability in planning. Next we focus on three more detailed issues, each of which can be seen as part and parcel of the abovementioned sustainability concept, but also as separate issues to merit deliberation in their own rights. 


\section{ADVANCED CONCEPTS: DIVERSITY, POLYCENTRICITY AND RESILIENCE}

One of the current debates of our time concerns the diversity concept and how it is being promoted in public planning paradigmatic discourse [28]. While this concept also belongs to a more formal scientific discourse, it can be noted that mathematical indices used in the natural world can also be used for the socio-economic world [29]. The greater the variety of subgroups is within a population of $X$, the more diverse this population is. In formal terms, of two areas with different number of categories, the area with more categories has more diversity. And, when using the urban ecologic definition, if the number of categories is the same for two areas, the area with more even distribution of these categories, in terms of their identifying characteristics, has more diversity [29].

Socio-culturally oriented urban research traditionally uses this concept in a less formal - and more loaded - manner [30]. Elsewhere, the New Economy is argued to affect the functional diversity and spatial structure of metropolitan regions [3132]. It can furthermore be argued that, for urban areas to be truly sustainable, both too little [33], and too much diversity [23], is likely to be harmful [34-36].

Polycentricity constitutes another contested concept in this realm. While polycentricity works on national and regional levels, the corresponding results on urban levels are not convincing. It is due to the persistent difficulty to relate this concept to the physical structure of cities in a meaningful way. (Going back to Petrişor's notion of the applicability of mathematical indices above, the same applies here: such tools can be used for measurement of polycentricity in socio-economic terms, just as they can be used for measurement of it in natural science terms.) What seems agreeable is that this concept has several dimensions, and can be approached using several conceptualizations, some of them more functionally and others more physically grounded. In this vein, De Goei and colleagues underscore the difference between two kinds of polycentricity [37]:

1. Interurban polycentricity, comprising an urban network (including the corridor city concept).

2. Intraurban polycentricity, based on a morphological polycentricism that determines the physical appearance of a city region.

According to Mihai Alexandru, despite the obvious shift away from urban centrality as the main organising urban and planning concept, polycentricity is not yet manifested in any general coherence of European metropolitan areas. He argued that this is due to the failure of urban models to account for the informality of urban mobility patterns. Thus, in this conceptualization the balance between centrifugal and centripetal forces that sort functions in urban space is increasingly directed by economic and social - and indeed technological - factors, but the physical plans lag behind. In this way, neither the over-planned city nor the neoliberal market city can lead us towards an authentic urban functionality; instead, we reach a manifestation of urban archipelagos, where sites are not connected with each other or with a central or polycentric overall structure, but only following top-down logic of either global capital investment or utopian design principles. Failure to sustain actual movements within urban space has negative consequences for urban development, Alexandru concluded [38]. 
A third kind of topical argumentation concerns the concept of resilience, so the ability of a system to cope with a serious problem. For example, how a coastal area can cope with damages caused by flooding, storm surge or tsunami. Considering the challenges ahead, the resilience concept is considered more developed in a rural context than in an urban one [39]. Nonetheless, when examining how the resilience idea is being taken up in the urban context, a number of specific issues have been identified. Among others: defining main criteria for developing an urban resilience assessment system [40]; expanding the discussion so as to deal with social and ecological issues together [41]; whether resilience is to be considered a positive or negative character [42]; that a city can be 'resilient in itself' or just 'managed in a resilient way' [43]; and the validity of the concept 'resilient city' [11]. Economic resilience, in turn, comprises a somewhat different concern for a city, as it is primary related to how the territorial economy can bounce back after a recession [44].

When summarizing essential resilience issues, Boštjan Kerbler picks six items [45]: spatial planning for climate change, restructuring of post-communist cities, revitalisation of parks and open spaces, role of migrants in transforming neighbourhoods, gated communities and intergenerational living. At the end of the day, the issue is about finding the apt spatial level to formulate and review the goals of resilience policy - a relatively well-researched topic already [46-51].

It is to note that resilience is not the same as sustainability, even if the two concepts usually are part of same discourses: the difference in systemic terms is that sustainability is about 'balancing the world', whereas resilience is about 'managing an imbalanced world' [29]. Following Eva-Maria Stumpp, the key to understanding the difference between sustainability and resilience is that the former concept can 'be made' whereas the latter 'happens' [52]. (Thus, it cannot 'be made'; only managed to a limited extent.) Elsewhere, Zhang and Li distinguish between the 'active process' of creating urban sustainability through a long time, and the 'passive process' of urban resilience aimed at problem solving [53]. (Thus in line with the definitions by Petrişor and Stumpp.)

Given the richness of the discussions above, it is evident that we need an interdisciplinary approach to deal with challenges in different realms, whether about diversity, polycentricity or resilience. We can also observe the relatively detailed arguments in this discussion, compared to the more general sustainability discussion earlier. Moreover, considering the lack of consensus concerning these three concepts, it is likely that key urban actors such as landowners and developers may have completely opposite ideals in this respect, even if they are neighbours. If this is the case, how justified is it then to use the tax-payer's money to fund any policy measures aimed at improving diversity, polycentricity or resilience in a given area?

\section{CONCLUSIONS}

In recent decades the whole planning apparatus has faced serious challenges such as inequality and exploitation of resources. It has been argued that such issues can only be solved, if we are open to new possibilities. Thus, it is our duty as planning analysts to be aware of potential problems and opportunities arising. Here technocratic awareness alone will hardly be enough; we must realize that community values are at stake, when the times are strongly encouraging narrow minded individualistic thinking. However, also this is only a partial story, because, if private 
investment is not allowed, a problem from economic growth - and indirectly also sustainable development - point of views will emerge.

Whereas sustainability is a concept that works on a general level, the three more advanced spatial development concepts discussed are strongly context dependent. How we exactly interpret them in planning and development discourse, therefore, much depends on the framing of details. Thus, in subsequent planning discourse the concepts of diversity, polycentricity and resilience are running the risk of becoming written in quotation marks. The absolute importance of these features, and the potential limitations to their applicability, are yet to be verified for any given community or development project. (In contrast, any confusion and disagreement pertaining to the sustainability concept seem less intense in comparison, although the reviewed literature does not provide certainty here.)

Often the most detailed issues can only be dealt with when they result from private investment aimed at incremental improvement and conversion at site-level. This can be concluded from the piecemeal development and ownership patterns resulting from organic market driven circumstances as opposed to larger scale public sector driven ones. When such an outcome is anticipated, a bottom-up strategy then is preferred to a top-down one. From this follows that, in the final analysis, our options are either, to attract private investment in order to reach the lofty goals of diversity, polycentricity and resilience, or to forget about these goals altogether and formulate more concrete ones instead - including perhaps, depending on the aim and timing, even government sponsored mega projects.

\section{References}

[1] van Rij, E., Korthals Altes, W. (2010), "Looking for the optimum relationship between spatial planning and land development". Town Planning Review, 81(3), 283-301.

[2] Upton, R. (2002), "Planning praxis - Ethics, values and theory". Town Planning Review, 73(3), 253-269.

[3] Enache, M. (2013), "Strategic Planning and decision: Modeling and Intuition", Center of Excellence in Planning (CEP) Applied Research Series, "Ion Mincu" Publishing House, Bucharest.

[4] Monk S., Whitehead C.M.E. (1999), "Evaluating the Economic Impact of Planning Controls in the United Kingdom: Some Implications for Housing". Land Economics, 75(1), 74-93.

[5] Healey P. (1991), "Models of the development process; a review". Journal of Property Research, 8, 219-238.

[6] Verhage, R. (2002), "Induced Cooperation in Housing Development: Comparing Housing Schemes in Four European Countries". European Planning Studies, 10(3), 305-320.

[7] Coyle, S.J. (2011), "The Process of Transformation. Sustainable Plan-making", in Coyle, S.J. \& Duany, A. (Eds.), Sustainable and Resilient Communities: A Comprehensive Action Plan for Towns, Cities, and regions. John Wiley and Sons Ltd, April, 25-31.

[8] Chapin, T.S. (2012), "From Growth Controls, to Comprehensive Planning, to Smart Growth: Planning's Emerging Fourth Wave". Journal of the American Planning Association, 78(1), 87-103.

[9] Green Leigh, N., Hoelzel, N.Z. (2012), "Sustainable Cities Need Productive 
Urban Industrial Land". Journal of the American Planning Association, 78(1), 87103.

[10] Schmid, W. (2017), "The importance of integrating energy and urban planning now". European Energy Innovation, 30-31.

[11] Anthony, A.F., Offia, I.E., Abidemi, B.R., Kamora, O.K.G. (2018), "Urban

Sustainability Concepts and Their Implications on Urban Form". Urban and Regional Planning, 3(1), 27-33.

[12] Antonescu, D. (2017), "Liveable city from an economic perspective". Journal of Urban and Landscape Planning, 10(2), 12-25.

[13] ICLEI (2017), "Energizing Smart and Sustainable Cities". Revolve, 24, 56-62.

[14] Marsh, Ch. (2010), "Planning Obligations and Social Sustainability", in Manzi,

T., Lucas, K., Lloyd-Jones, T. \& Allen, J., Social Sustainability in Urban Areas.

Communities, Connectivity and the Urban Fabric, Earthscan, London and Washington D.C., 161-181.

[15] Manzi, T., Lucas, K., Lloyd-Jones, T., Allen, J. (Eds) (2010), Social Sustainability in Urban Areas. Communities, Connectivity and the Urban Fabric, Earthscan, London and Washington D.C..

[16] Manzi, T. Lucas, K., Lloyd-Jones, T., Allen, J. (2010), "Understanding Social Sustainability: Key Concepts and Developments in Theory and Practice", in Manzi, T., Lucas, K., Lloyd-Jones, T. \& Allen, J. (Eds), Social Sustainability in Urban Areas. Earthscan, London and Washington D.C., 1-28.

[17] Bailey, N. (2010), "Building Sustainable Communities from the Grassroots: How Community Land Trusts Can Create Social Sustainability", in Manzi, T., Lucas, K., Lloyd-Jones, T. \& Allen, J. (Eds), Social Sustainability in Urban Areas. Earthscan, London and Washington D.C., 49-64.

[18] Allen, J., Lloyd-Jones, T. (2010), "Neighbourhood Asset Management: Life Cycles and Learning for Social Sustainability", in Manzi, T., Lucas, K., Lloyd-Jones, T. \& Allen, J. (Eds), Social Sustainability in Urban Areas. Earthscan, London and Washington D.C., 65-82.

[19] Hamiduddin, I. (2015), "Social sustainability, residential design and demographjic balance: neighbourhood planning strategies in Freiburg, Germany". Town Planning Review, 86(1), 29-52.

[20] Talen, E. (2011), "Sprawl retrofit: sustainable urban form in unsustainable places". Environment and Planning B, 38, 952--978.

[21] Bramley, G., Power, S. (2009), "Urban form and social sustainability: the role of density and housing type". Environment and Planning B: Planning and Design, 36(9), 30-48.

[22] Bramley, G., Dempsey, N., Power, S., Brown, C., Watkins, D. (2009), "Social sustainability and urban form: evidence from five British cities". Environment and Planning A, 41, 2125-2142.

[23] Bitušiková, A., Luther, D. (2010), "Sustainable diversity and public space in the city of Bratislava, Slovakia". Anthropological Notebooks, 16(2), 5-18.

[24] Colantonio, A., Dixon, T. (2011), Urban Regeneration and Social Sustainability: Best Practice from European Cities. RICS Research, Wiley-Blackwell. Chapters 1-4, 3-79.

[25] Williams, K. (2010), "Sustainable cities: research and practice challenges". International Journal of Urban Sustainable Development, 1(1-2), 128-132.

[26] Keivani, R. (2009), "A review of the main challenges to urban sustainability". International Journal of Urban Sustainable Development, 1(1-2), 5-16.

[27] Holden, M. (2010), "The Rhetoric of Sustainability: Perversity, Futility, 
Jeopardy?" Sustainability, 2, 645-659.

[28] Perin, L., Grant, J. (2013), "Perspectives on mixing housing types in the suburbs". Town Planning Review, 85(3), 363-385.

[29] Petrişor, A.-I. (2017), "A diversity-based approach to the spatial development of socio-ecological systems". Urbanism Architecture Constructions, 8(2), 143-162. [30] Zukin, S. (1998) "Urban Lifestyles: Diversity and Standardisation in Spaces of Consumption". Urban Studies, 35(5-6), 825-839.

[31] Bontje, M., Burdack, J. (2005), "Edge Cities, European-style: Examples from Paris and the Randstad". Cities, 22(4), 317-330.

[32] Dijkstra, L. (2009), Metropolitan regions in the EU. European Union Regional Policy, 01/2009.

[33] Foxon, T. J., Köhler, J., Michie, J., Oughton, Ch., (2013), "Towards a New Complexity Economics for Sustainability". Cambridge Journal of Economics, 37(1), 187-208.

[34] Kauko, T. (2014a), "Towards Evolutionary Economic Analysis of Sustainable Urban Real Estate: Concept of a research strategy, exemplified on house price modeling using the self-organizing map, interviews and field inspection", in Wallot, C., Gurr, J.M. \& Schmidt, J.A. (Eds.), Understanding Complex Urban Systems: Multidisciplinary Approaches to Modeling. Springer, Switzerland, 67-86.

[35] Kauko, T. (2014b), "Sustainability of micro-locations vs. house price premiums in a post-socialist/CEE city", Journal of Sustainable Real Estate, 5, 1-66, available at http://www.josre.org/wp-content/uploads/2012/09/Tom-Kauko-JOSREsubmission-20july-2013.pdf [accessed 30 March 2020].

[36] Kauko, T. (2015), "An evaluation of the management of Budapest district VIII and IX urban regeneration area based on property prices, inspection and narratives", in Woltjer, J., Alexander, E., Hull, A. \& Ruth, M. (Eds), Place-Based Evaluation for Integrated Land-Use Management. Ashgate, 345-375.

[37] De Goei, B., Burger, M.J., Van Oort, F.G., Kitson, M. (2010), "Functional Polycentrism and Urban Network Development in the Greater South East, United Kingdom, Evidence from Commuting Patterns". Regional Studies, 44(9), 11491170.

[38] Alexandru M.C. (2014), "Polycentricity and Metropolitan coherence" (PhD Thesis), "Ion Mincu" University of Architecture and Urban Planning, Bucharest, Romania.

[39] Collier, M.J., Nedović-Budić, Z., Aerts, J., Connop, S., Foley, D., Foley, K., Newport, D. etc. (2013), "Transitioning to resilience and sustainability in urban communities". Cities, 32, S21--S28.

[40] Sharifi, A., Yamagata, Y. (2014), "Resilient urban planning: Major principles and criteria". Energy Procedia, 61, 1491-1495.

[41] Beilin, R., Wilkinson, C. (2015), "Introduction: Governing for urban resiience". Urban Studies, 52(7), 1205-1217.

[42] Meerow, S., Newell, J.P., Stults, M. (2016), "Defining urban resilience: A review". Landscape and Urban Planning, 147, 38-49.

[43] Spaans, M., Waterhout, B. (2017), "Building up resilience in cities worldwide Rotterdam as participant in the 100 Resilient Cities Programme". Cities, 61, 109116.

[44] Antonescu, D., Ciocănel, B. (2018), "Territorial resilience: An economic perspective", Journal of Urban and Landscape Planning, 10(3), 51-60. 
[45] Kerbler, B. (2016), "Revitalisation of open spaces, changing centralities and neighbourhoods, and the importance of spatial planning for climate change adaption". Urbani izziv, 27(1), 89-94.

[46] Coaffee, J. (2013), "Rescaling and Responsibilising the Politics of Urban Resilience: From National Security to Local Place-Making". Politics, 33(4), 240-252. [47] Johnson, C., Blackburn, S. (2014), "Advocacy for urban resilience: UNISDR's Making Cities Resilient Campaign". Environment \& Urbanization, 26(1), 29-52. [48] Bandyopadhyay, Ch., Philip, P.J. (2015), "A Safe City approach to urban sustainabilitty: Developing a framework for community resilience". Indian Journal of Public Administration, LXI(1), 40-56.

[49] Chelleri, L. Waters, J.J., Olazabal, M., Minucci, G. (2015), "Resilience tradeoffs: addressing multiple scales and temporal aspects of urban resilience".

Environment \& Urbanization, 27(1), 181-198.

[50] Wagenaar, H., Wilkinson, C. (2015), "Enacting Resilience: A Performative Account of Governing for Urban Resilience". Urban Studies, 52(7), 1265-1284. [51] Keller, A., Chieffo, N., Opritescu, E., Mosoarca, M., Formisano, A. (2017), "Resilience of Historic Cities and Adaptation to Climate Change". Urbanism Architecture Constructions, 8(1), 15-26.

[52] Stumpp, E.-M. (2013), "New in town? On resilience and "Resilient Cities"'". Cities, 32, 164-166.

[53] Zhang, X., Li, H. (2018) "Urban resilience and urban sustainability: What we know and what do not know?" Cities, 72, 141-148.

\section{Article distributed under a Creative Commons Attribution-}

NonCommercial-NoDerivatives 4.0 International License (CC BY-NC-ND). Received: April 6, 2020

Accepted: October 11, 2020, revision October 18, 2020 